\title{
PREVALENCE OF DEPRESSION IN HOSPITALIZED PATIENTS OF PULMONARY TUBERCULOSIS
}

\author{
Gulzar Ali, Imran Khan, Muhammad Amir, Malik Nadeem Azam Khan* \\ Combined Military Hospital Peshawar/National University of Medical Sciences (NUMS) Pakistan, *Pak Emirates Military Hospital/National \\ University of Medical Sciences (NUMS) Rawalpindi Pakistan
}

\begin{abstract}
Objective: To find the prevalence of depression in admitted patients of pulmonary tuberculosis.

Study Design: Cross-sectional study.

Place and Duration of Study: Tuberculosis centre, Pak Emirates Military Hospital Rawalpindi and Medicine department Combined Military Hospital Peshawar, from Dec 2017 to May 2018.

Methodology: One hundred and six patients of both genders admitted due to pulmonary tuberculosis for more than 2 weeks were taken into study. Individuals on treatment for depression before diagnosis of tuberculosis on medical records and patients with chronic debilitating diseases liable to depression were excluded. All patients were interviewed and scored on Hamilton Depression Rating Scale. Data was noted on especially designed proforma. Statistical analysis was done on SPSS-22.

Results: Mean age of the patients was $37.452 \pm 9.26$ years with range from 20 to 60 years. Mean duration of tuberculosis was $4.283 \pm 1.21$ months and mean duration of hospitalization was $3.584 \pm 0.65$ weeks while mean weight was $70.839 \pm 8.85 \mathrm{Kg}$. Majority of the patients were male $54(50.9 \%)$ and married $79(74.5 \%)$. Depression was seen in $45(42.5 \%)$ patients.

Conclusion: The effects of chronic diseases such as tuberculosis are not only physical but also include mental health dysfunction which can lead to poor drug compliance and ultimately drug resistance. In our study depression was recorded in $42.5 \%$ of patients hospitalized for treatment of tuberculosis. Thus, all admitted patients of tuberculosis should be screened for depression and managed in collaboration with psychiatrist.
\end{abstract}

Keywords: Depression, Pulmonary tuberculosis, Prevalence.

This is an Open Access article distributed under the terms of the Creative Commons Attribution License (http://creativecommons.org/licenses/by/4.0), which permits unrestricted use, distribution, and reproduction in any medium, provided the original work is properly cited.

\section{INTRODUCTION}

Mycobacterium tuberculosis is the causative pathogen for tuberculosis (TB) which can affect virtually any system of the human body. TB is the leading cause of morbidity and mortality around the globe ${ }^{1,2}$. World Health Organization (WHO) estimated (in 2017), that 10 million individuals developed TB in year 2017, leading to 1.3 million deaths in HIV negative people worldwide ${ }^{3}$. TB is the second leading cause of mortality among the infections after HIV/ AIDS4.

The effects of pulmonary tuberculosis are not limited to physical disability only but also affects mental health. As TB is highly infectious therefore patients need to be isolated which lead to social rejection, low self confidence and negative

Correspondence: Dr Gulzar Ali, Resident Medicine, Combined Military Hospital, Rawalpindi Pakistan

Received: 15 May 2019; revised received: 10 Oct 2019; accepted: 18 Oct 2019 emotions specially in hospitalized patients. TB is a transmissible and enfeebling condition with many unfavorable outcomes ${ }^{5}$. Consequently patients are prone to anxiety and depression due to the historic social stigma of necessary isolation. In recent research individuals with pulmonary tuberculosis were found to have increased prevalence of depression, anxiety, solitude, and reduced quality of life levels which badly affects adherence to treatment of TB6-8.

Balaji et al found in a study that frequency of depression was $39.5 \%$ in admitted cases of pulmonary tuberculosis9. Peltzer et al found in another study that prevalence of depression was $81 \%$ in hospitalized patients of pulmonary tuberculosis ${ }^{10}$, while Amreen et al found it to be $56 \%$ in 2014 at Karachi, Pakistan ${ }^{11}$.

This aspect of TB treatment lacks the attention of researchers in our population. Only one 
study from Karachi is reported on the subject so far ${ }^{11}$. Furthermore in one study prevalence of depression in TB was 39.5\% $81 \% 10$, which cannot be generalized. Therefore, we planned to find the frequency of depression in hospitalized individuals of pulmonary tuberculosis by testing the hypothesis that depression is prevalent in cases of pulmonary tuberculosis. This will also provide other researchers the background for addressing depression in pulmonary TB patients leading to better adherence to treatment.

\section{METHODOLOGY}

The study was carried out in tuberculosis center Pak Emirates Military Hospital Rawalpindi and Combined Military Hospital Peshawar, from December 2017 to May 2018. One Hundred and six patients (both male and female) hospitalized for pulmonary tuberculosis for more than 2 weeks were selected using non-probability consecutive sampling technique. Sample size was calculated by using WHO (World health organization) sample size calculator with confidence level of $95 \%$ and expected least proportion (depression) $p=81 \%^{10}$. Age limit was between 20-60 years. Patient undergoing documented treatment for depression prior to TB and patients suffering from other chronic debilitating diseases were not included.

After permission from ethical council (IERB approval certificate number-CMHPSC/0010), Demographic data (name, gender, age, weight (on weighing machine) was recorded. Informed consent was obtained from each individual participating in study, with the fact that there was no risk involved to the patient and confidentiality was assured. The privacy of the patients was further ensured by interviewing them one by one in the counseling room in the presence of a chaperon where needed.

All patients were interviewed and scored on HDRS (Hamilton Depression Rating Scale) as it is the most widely used clinician-administered depression assessment scale. Data was noted on especially designed Performa.
Data analysis was performed on statistical programme IBM-SPSS version 22. The qualitative variables like gender, marital status and Depression were presented by calculating frequency and percentages. The quantitative variables like age, duration of $\mathrm{TB}$, duration of hospitalization and weight were presented by calculating mean and standard deviation. Effect modifiers like age, gender, marital status duration of $\mathrm{TB}$, duration of hospitalization and weight were stratified. After stratification chi square test was applied and $p \leq 0.05$ was counted statistically significant.

\section{RESULTS}

Depression was detected in 45 (42.5\%) patients (figure). Mean age of the patients was 37.452 \pm 9.26 years, ranging from 20 to 60 years. Mean

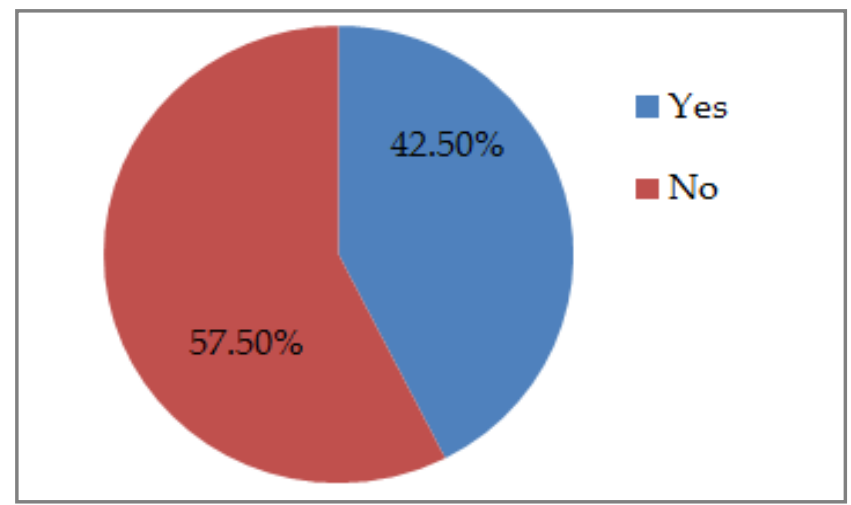

Figure-I: Percentage of patients according to depression (n-106).

Table-I: Mean \pm SD of age, duration of tuberculosis, duration of hospitalization and weight of the patients in study $(n=106)$.

\begin{tabular}{c|l|c}
\multicolumn{2}{l|}{ Demographics } & Mean \pm SD \\
\hline 1 & Age (years) & $37.452 \pm 9.26$ \\
\hline 2 & Duration of TB (months) & $4.283 \pm 1.21$ \\
\hline 3 & $\begin{array}{l}\text { Duration of hospitalization } \\
\text { (weeks) }\end{array}$ & $3.584 \pm 0.65$ \\
\hline 4 & Weight (Kg) & $70.839 \pm 8.85$ \\
\hline
\end{tabular}

Duration of TB was $4.283 \pm 1.21$ months, mean Duration of hospitalization was $3.584 \pm 0.65$ weeks and mean weight was $70.839 \pm 8.85 \mathrm{Kg}$ (table-I). Majority were male $(50.9 \%)$ and married (74.5\%). Effect modifiers like age, gender, marital status, Duration of TB, Duration of hospitalization and weight were stratified (table-II). The percentage of patients affected by depressive symp- 
toms was more among younger age group, unmarried females and those who remained admitted for longer duration (table-II). Among those depressed majority were severely depressed (table-III). sion in such patients is missed as this is not their primary complaint leading to poor drug compliance. However in our study the frequency of depression was lower than $56 \%$ found by Amreen et al in 2014 at Karachi, Pakistan ${ }^{11}$. This

Table-II: Stratification of depression with respect to age, gender, marital status, duration of TB, duration of hospitalization and weight groups (n-106).

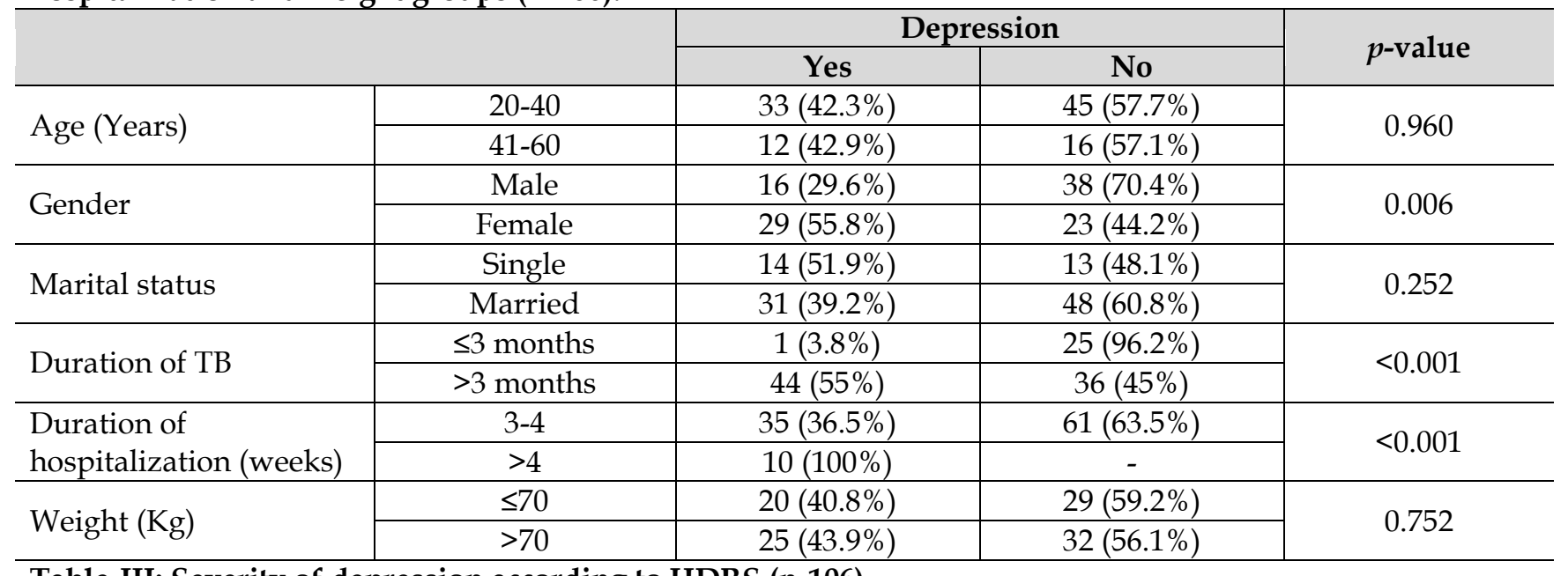

Table-III: Severity of depression according to HDRS (n-106).

\begin{tabular}{l|c|c|c|c|c}
\hline $\begin{array}{l}\text { Normal } \\
\text { HDRS-0 }\end{array}$ & $\begin{array}{c}\text { Minimal } \\
\text { HDRS (1-4) }\end{array}$ & $\begin{array}{c}\text { Mild } \\
\text { HDRS (5-9) }\end{array}$ & $\begin{array}{c}\text { Moderate } \\
\text { HDRS (10-14) }\end{array}$ & $\begin{array}{c}\text { Moderately Severe } \\
\text { HDRS (15-19) }\end{array}$ & $\begin{array}{c}\text { Severe } \\
\text { HDRS (20-27) }\end{array}$ \\
\hline $61(57.5 \%)$ & $5(4.7 \%)$ & $8(7.5 \%)$ & $10(9.4 \%)$ & $7(6.6 \%)$ & $15(14.5 \%)$ \\
\hline
\end{tabular}

\section{DISCUSSION}

Our study was aimed to find the frequency of depression among TB patients and reported a frequency of $42.5 \%$. The study further indicated that younger age group, female gender, extensive pathology, long period of illness and marital status as risk factors for depression in patients of TB.

The frequency of depression found in this study among hospitalized TB cases $(42.5 \%)$ was lower than $52.5 \%$ outlined in an earlier research paper in Nigeria ${ }^{12}$, also less than $54.0 \%$ recorded by Ambaw et al13 in Ethiopia as well as much lower than $68 \%$ found in South Africa ${ }^{14}$. However, in comparison to Natani et al15, who found the frequency of only $8 \%$, our patients were severely depressed, $14.5 \%$ found severely depressed. These gravely depressed individuals are always at high risk of suicide. Resultantly, the TB ward/clinic is a place where depression can be diagnosed frequently. Most of the time depres- may be attributable to the availability of free treatment to our patients in military hospitals.

The association of depression with long illness duration was similar to Natani et al ${ }^{15}$ and was significant. In relation to gender, we found similar results to that of Issa et al16, but contrasts that of Natani et al ${ }^{15}$ who reported no gender difference in the frequency of depression in TB.

The results in our study indicated the increased presence of depression in TB patients. In this study we found high frequency of depression in admitted TB cases which may be partly because we studied depressive symptoms instead of major depressions, as compared to other studies. The specificity and high sensitivity of the screening tool (HDRS) used in this study may be the other reason of increased depression in the sample studied. The different prevalence rates among various studies could also be attributed to variations in study designs and patient parameters. It is pertinent to manage the mental health of $\mathrm{TB}$ 
patients as one third of such patients experience depressive symptoms at some point in the course of treatment. In addition hospitalization for long time may be the cause of increased number of cases of depression in our study. The need for isolation, the relation between disease activity and depression, as well as the presence of other concomitant infections (like TB/HIV together) were likely the causes of increased prevalence in admitted cases of $\mathrm{TB}^{17}$.

There was increased frequency of depression in TB cases among patients of 20-40 years of age, although this relation was unremarkable in the multivariate analysis. Walker et al in Nepal found the same results in the age bracket of 23-43 years, mostly found depressed 18 , though Basu et al in India ${ }^{19}$ and Santos et al in South korea ${ }^{20}$ found depression in elder population. Similarly, Adem et al in Ethiopia ${ }^{21}$ and Wang, Xiao-Bo et al in China $^{22}$, found depression in relatively older age people suffering from TB. In our research mostly young patients were studied as it was carried out in urban settings, comprised majority of youth. Depression was more prevalent in those admitted for longer duration in the hospital as seen by Shyamala et al in India ${ }^{23}$.

This aspect of tuberculosis patients has not been done very often in Pakistan as well as around the world particularly in Drug Resistant TB which needs further work dedicatedly.

\section{CONCLUSION}

In conclusion, the impact of chronic diseases such as tuberculosis extends beyond physical impairment. Patient with tuberculosis are prone to depression particularly when hospitalized for longer duration. This can lead to poor compliance and drug resistance. Thus, the care of patients with tuberculosis should be comprehensive and include psychiatric care.

\section{CONFLICT OF INTEREST}

This study has no conflict of interest to be declared by any author.

\section{REFERENCES}

1. Fogel N. Tuberculosis: a disease without boundaries. Tuberculosis (Edinb) 2015; 95(5): 527-31.
2. Getnet F, Demissie M, Assefa N, Mengistie B, Worku A. Delay in diagnosis of pulmonary tuberculosis in low-and middle-income settings: systematic review and meta-analysis. BMC Pulm Med 2017; 17(1): 202.

3. World Health Organization. Global tuberculosis report 2018 Geneva, Switzerland: World Health Organization; 2018.

4. Churchyard G, Kim P, Shah NS, Rustomjee R, Gandhi N, Mathema B, et al. What We Know About Tuberculosis Transmission: An Overview. J Infect Dis 2017; 216(Suppl_6): S629-S35.

5. Kibrisli E, Bez Y, Yilmaz A, Aslanhan H, Taylan M, Kaya H, et al. High social anxiety and poor quality of life in patients with pulmonary tuberculosis. Medicine (Baltimore) 2015; 94(3): e413.

6. Mason PH, Sweetland AC, Fox GJ, Halovic S, Nguyen TA, Marks GB. Tuberculosis and mental health in the Asia-Pacific. Australas Psychiatr 2016; 24(6): 553-55.

7. Sweetland AC, Kritski A, Oquendo MA, Sublette ME, Norcini Pala A, Silva LRB, et al. Addressing the tuberculosis-depression syndemic to end the tuberculosis epidemic. Int J Tuberc Lung Dis 2017; 21(8): 852-61.

8. Thomas BE, Shanmugam P, Malaisamy M, Ovung S, Suresh C, Subbaraman R, et al. Psycho-Socio-economic issues challenging multidrug resistant tuberculosis patients: A systematic review. PLoS One 2016; 11(1): e0147397.

9. Balaji AL, Abhishekh HA, Kumar NC, Mehta RM. Depression in patients with pulmonary tuberculosis in a tertiary care general hospital. Asian J Psychiatr 2013; 6(3): 251-52.

10. Peltzer K, Naidoo P, Matseke G, Louw J, McHunu G, Tutshana B. Prevalence of psychological distress and associated factors in tuberculosis patients in public primary care clinics in South Africa. BMC Psychiatr 2012; 12(1): 89.

11. Amreen NR. Frequency of depression and anxiety among tuberculosis patients. J Tuberc Res 2016; 4(1): 183-90.

12. Aghanwa HS, Erhabor GE. Demographic/socioeconomic factors in mental disorders associated with tuberculosis in southwest Nigeria. J Psychosom Res 1998; 45(4): 353-60.

13. Ambaw F, Mayston R, Hanlon C, Alem A. Burden and presentation of depression among newly diagnosed individuals with TB in primary care settings in Ethiopia. BMC Psychiatr 2017; 17(1): 57.

14. Westaway MS, Wolmarans L. Depression and self-esteem: rapid screening for depression in black, low literacy, hospitalized tuberculosis patients. Soc Sci Med 1992; 35(10): 1311-15.

15. Natani G, Jain N, Sharma T, Gehlot P, Agrawal S, Koolwal S, et al. Depression in tuberculosis patients: correlation with duration of disease and response to anti-tuberculous chemotherapy. Indian J Tuberc 1985; 32(4): 195-98.

16. Issa BA, Yussuf AD, Kuranga SI. Depression comorbidity among patients with tuberculosis in a university teaching hospital outpatient clinic in Nigeria. Ment Health Fam Med 2009; 6(3): 133.

17. Kehbila J, Ekabe CJ, Aminde LN, Noubiap JJN, Fon PN, Monekosso GL. Prevalence and correlates of depressive symptoms in adult patients with pulmonary tuberculosis in the southwest region of Cameroon. Infect Dis Poverty 2016; 5(1): 51.

18. Walker I, Kanal S, Baral S, Farragher T, Joshi D, Elsey H, et al. Depression and anxiety in patients with multidrug-resistant tuberculosis in Nepal: an observational study. Public Health Action 2019; 9(1): 42-48.

19. Basu G, Chatterjee C, Singh R, Biswas S. Prevalence of depression in tuberculosis patients: an experience from a DOTS clinic. Indian J Res Rep Med Sci 2012; 2(4): 14-17.

20. Santos APCd, Lazzari TK, Silva DR. Health-related quality of life, depression and anxiety in hospitalized patients with tuberculosis. Tuberc Respir Dis 2017; 80(1): 69-76. 
21. Adem A, Markos T, Mohammed A. The prevalence and pattern of depression in patients with tuberculosis on follow-up at jimma university specialized hospital and jimma health center. Med Sci 2013; 3(1): 955-68.

22. Wang XB, Li XL, Zhang Q, Zhang J, Chen HY, Xu WY, et al. A Survey of Anxiety and depressive symptoms in pulmonary tuberculosis patients with and without tracheobronchial tuberculosis. Front Psychiatr 2018; 9(1): 308.

23. Shyamala KK, Naveen RS, Khatri B. Depression: A neglected comorbidity in patients with tuberculosis. J Assoc Physicians India 2018; 66(12): 18-21. 